\title{
Can Incentive Effects in Web Surveys be Generalized to Non-Western \\ Countries? Conditional and Unconditional Cash Incentives in a Web \\ Survey of Ghanaian University Students
}

\author{
Bart Meuleman ${ }^{1,2,5}$, Arnim Langer ${ }^{1,3}$ \& Annelies G. Blom ${ }^{4,5}$
}

${ }^{1}$ Centre for Research on Peace and Development (CRPD), University of Leuven

${ }^{2}$ Centre for Sociological Research (CeSO), University of Leuven

${ }^{3}$ Leuven International and European Studies (LINES), University of Leuven

${ }^{4}$ Department of Political Science, School of Social Sciences, University of Mannheim

${ }^{5}$ Collaborative Research Centre "Political Economy of Reforms" (SFB 884), University of Mannheim

\section{Accepted for publication in Social Science Computer Review}

\begin{abstract}
Because research on the impact of web survey incentives has exclusively focused on Western settings, it is unclear to what extent current insights translate and generalize to non-Western societies, which are usually characterized by very different economic conditions, cultural traditions and survey climates. The current paper presents the results of a web survey incentives experiment among almost 4,440 Ghanaian university students who were offered conditional and unconditional incentives of different values (in the form of telephone credit). Our analyses partly replicate Western findings: higher value incentives produce higher participation rates and unconditional incentives outperform conditional ones in the lower value conditions. In the case of relatively high incentives, however, conditional outperform unconditional incentives. No differential effects of incentives on response quality were found.
\end{abstract}

Key words: incentives experiment; conditional vs. unconditional incentives; nonresponse; response quality, web survey; Ghana 


\title{
Can Incentive Effects in Web Surveys be Generalized to Non-Western \\ Countries? Conditional and Unconditional Cash Incentives in a Web \\ Survey of Ghanaian University Students
}

\begin{abstract}
Introduction
In a few years, research into the impact of incentives on survey participation will celebrate its centenary. As early as 1931, the first quasi-experimental study on including a 25cent coin in a mail survey was published by Shuttleworth (1931). Over the decades, countless survey experiments have gathered sound empirical evidence that incentives can be a powerful tool for increasing response rates (for meta-analyses see Auspurg \& Schneck 2014; Church 1993; Göritz 2006a; Edwards et al. 2002; Hopkins and Gullickson 1992; Singer et al. 1999; Yu \& Cooper 1983). In a nutshell, available research convincingly shows that (1) incentives increase response rates, irrespective of the survey mode used; (2) unconditional (prepaid) incentives are more effective than conditional (promised) incentives; (3) monetary incentives are more effective than vouchers and in-kind incentives; and (4) the higher value of an incentive, the stronger is the effect it produces, albeit marginal returns diminish (Singer and Ye 2013). More recently, researchers have also started enquiring the effect of incentives on indicators of response quality, notably on item nonresponse (Curtin, Singer, and Presser 2007; Davern et al. 2003; Medway 2012).

Although the quantity of empirical evidence is impressive, the available research is geographically - and as a result also culturally - very strongly clustered. The vast majority of studies were carried out in the U.S. or - to a lesser extent - in other Anglo-Saxon countries, such as Canada, the UK or Australia, and a few Western European countries. This raises the question to what extent current knowledge regarding incentive effects can be translated cross-
\end{abstract}


nationally (Blom, Jäckle, and Lynn 2010; Couper and de Leeuw, 2003). After all, "the meaning of gifts as well as monetary incentives is likely to differ between cultures" (Singer et al. 1999, p. 219), and the scarce available comparative research suggests that even within the Anglo-Saxon world incentive effects show cross-national variation (Mutti et al. 2014). The generalizability of incentive effects beyond the Western world raises even greater question marks, in particular, in the context of web surveys. How effective are incentives in web surveys in non-Western societies that are characterized by very different economic conditions, cultural traditions and survey climates?

The present study contributes to this field by analysing an incentives experiment implemented in the National Service Scheme Survey (N3S), a web survey conducted between in August 2014 among 4,440 Ghanaian university students, who were offered conditional and unconditional incentives of different values. The incentives were quasi-cash, in the form of top-up credits for mobile phones, a typical means of transferring small amounts of money in Ghana. We examine whether and to what extent the web survey incentives have an impact on survey participation and response quality. To the best of our knowledge, this study is the first to report the results of a web survey incentives experiment in an African country. It, therefore, sheds light on whether the well-documented findings from Western countries can be transferred to non-Western settings.

This paper commences with a brief review of the theory and previous research on the impact of incentives on response rates and data quality in Western countries. In the theory section, we also elaborate on the specificity of the Ghanaian context and derive research hypotheses. Subsequently, we describe the design of the study and present our results. We conclude with a discussion of the implications of our study. 
Theory and Hypotheses

\section{Effects of Incentives on Response and Response Quality: Theoretical Perspectives}

In the context of unit nonresponse, leverage-salience theory stresses that decisions to accept or refuse partaking in a survey depend on a wide array of factors - such as topic, sponsorship, expected time investment, concerns about privacy, perceived benefits and community involvement - that have "different 'leverages' on the cooperation decision for different persons" (Groves, Singer and Corning 2000, p. 306). One of these levers that can be relatively easily operated by survey designers is giving incentives to respondents. Numerous studies have successfully used incentives - varying in form (monetary vs. in kind) and conditionality (unconditional vs. conditional; Church 1993) - to stimulate survey response.

To explain the effectiveness of incentives on response rates, two theoretical frameworks that stress different mechanisms - namely self-interest vs. norms of reciprocity compete for attention (Singer and Ye 2013). First, according to rational choice-based approaches, such as exchange theory (Homans 1950) or the theory of reasoned action (Fishbein and Ajzen 1975), individual behaviour is rooted in rational cost-benefit calculations (Alwin 1991: 17-18; Philipson 1997; Singer 2011). Providing an incentive to respondents adds to the benefit-side, and consequently increases the probability that a person will take part in the survey. This rational choice-approach stresses the importance of the monetary value and conditionality of incentives. The more valuable an incentive is, the higher the probability that it can tip the balance in favour of survey participation. The incentive should only be provided conditional upon completion of the survey. Once handed over, the incentive disappears from the cost-benefit equation and it is no longer in the self-interest of the respondent to cooperate.

A second approach contradicts the premise that the effectiveness of incentives can be fully understood by referring to the realm of the economic only. Providing incentives is not a 
neutral transaction of economic value, but establishes a social relation of trust and appeals to the principle of the Gift (Mauss 1923). Incentives establish a norm of reciprocity: They create a moral obligation to reciprocate the favour by participating in the survey (Gouldner 1960). Even small symbolic values can be effective, and the incentive should be given prior to participation in the survey (i.e. unconditionally; Dillman 2000).

Incentives do not only affect the decision to participate in a survey, but could also have an impact on response behaviour during the survey. Reasoning along the two theoretical frameworks presented above, contrasting expectations have been uttered (Singer and Ye 2013). Some scholars have expressed the concern that incentives might have detrimental effects on response quality, because they persuade sample units who would otherwise have refused to respond. Assuming that incentives affect the decision to participate but not the respondents' motivation, these respondents lack internal motivation and might therefore not fill out the survey carefully, which leads to incomplete data of low quality (Davern et al. 2003; Deutskens et al. 2004; Göritz 2006a). Hansen (1980, p. 78) uses self-perception theory to explain such quality-reducing effect of incentives: External motivators (such as incentives) impede respondents from perceiving themselves as cooperative persons, which results in less effort during the survey. If, however, incentives activated a norm of reciprocity, their effectiveness would not be confined to the cooperation decision, but would instead extend across the whole survey. In this case, incentives would stimulate respondents to provide more complete and adequate information, and improve response quality (Davern et al. 2003).

\section{Empirical Evidence From the Western World}

In the Western World (mostly the U.S.), the theoretical propositions on incentive effects have been tested elaborately among the general population as well as more specific samples -such as adolescents (Jäckle and Lynn 2008), university students (Shettle and 
Mooney 1999; van Veen, Göritz, and Sattler 2016), or even earthquake engineers (Birnholtz et al. 2004). Several reviews (Simmons and Wilmot 2004; Singer and Ye 2013) and metaanalyses (Armstrong and Lusk 1987; Church 1993; Göritz 2006a; Heberlein and Baumgartner 1978; Singer et al. 1999; Yu and Cooper 1983) reveal a general pattern that confirms components of both theoretical frameworks. Incentives tend to motivate respondent cooperation, irrespective of whether the survey is interviewer-mediated (Singer et al. 1999), administered via mail (Church 1993) or web (Göritz 2006a) and of whether data-collection is cross-sectional or longitudinal (Jäckle and Lynn 2008).

The exact effectiveness of an incentive, however, depends on its form, conditionality, and value. Prepaid (unconditional) incentives are found to be considerably more effective at increasing response rates than promised (conditional) incentives (Singer et al. 1999; Yu and Cooper 1983), even when keeping the overall costs equal (e.g. Blom, Gathmann and Krieger 2015). Some studies even report that promised incentives do not yield higher response rates than no-incentive comparison groups (e.g. Church 1993). Equally in line with the reciprocityargument is that incentives with small, symbolic value already increase response substantially. Higher values, however, tend to produce stronger response-inducing effects, which can be understood from rational choice theory. Empirical evidence on the functional form of the relationship between incentive value and response rates is mixed. While some studies report that response increases linearly with incentive values (Church 1993; Yu and Cooper 1983; Gelman, Stevens \& Chan 2003), others report diminishing marginal returns (Dillman 2000; Singer et al. 1999) and are no longer effective beyond a certain threshold (James and Bolstein 1992). Finally, cash incentives have stronger motivating effects than incentives in kind of the same value (Singer et al. 1999; Yu and Cooper 1983), which supports the economic argument. 
The effect size of incentives also depends on the survey mode. Regarding unit nonresponse, incentives tend to be most effective in mail surveys. Church's (1993) metaanalysis reveals that prepaid incentives of small value (mean value $1.38 \$$ ) increase response rates by 19.1 percentage points, which implies a $65 \%$ bump in response rate (effect size $d=.347$ ). Singer et al. (1999) report that, across 39 interviewer-mediated surveys, every dollar of incentive paid yields more or less one third of a percentage point in response rate. A possible explanation for this considerably weaker effect might be that interviewer-mediated surveys generally have higher base-line response rates.

With regards to web surveys, a meta-analysis by Göritz (2006a) shows that the odds of starting and completing a web survey increase with $19 \%$ and $27 \%$, respectively (corresponding to effect sizes $d$ of .10 and .13), when an incentive is provided. The comparatively weak effects in web surveys might be related to the difficulty of establishing trust over the internet combined with the fact that it is practically difficult to provide cash incentives to online respondents. Web-suitable unconditional incentives (such as payments through PayPal or vouchers for online purchases) often require relatively lengthy procedures and high levels of internet literacy (Bosnjak and Tuten 2003) or an offline pre-recruitment phase, where addresses of sample units, to which the unconditional incentive can be sent, are collected (Scherpenzeel and Toepoel 2012). The few studies on unconditional cash incentives (Bosnjak and Tuten 2003; Scherpenzeel and Toepoel 2012) show mixed results.

Whereas there is abundant evidence for response-increasing effects of (unconditional monetary) incentives, fewer studies look into the relationship between incentives and response quality. Often-used indicators of response quality are (the absence of) item nonresponse or the length of answers in open-ended questions (Singer and Ye, 2013). Various studies report that the use of incentives does not affect item nonresponse (e.g. Curtin et al. 2007; Davern et al. 2003; Göritz 2004; Petrolia and Bhattacharjee 2009; Teisl, Roe and Vayda 
2005), while others find that incentives motivate respondents to complete all questions (Bosnjak and Tuten 2003; James and Bolstein 1990; Medway 2012; Singer, van Hoewyk and Maher 2000). In any case, the available research does not support the argument that giving out incentives harms response quality. If they have any effect on response quality, incentives seem to strengthen rather than to undermine respondents' motivation. The effect of different types of incentives on response quality remains unclear.

\section{Potential Differences in the Ghanaian Context}

A crucial limitation in the field is that available research tends to be restricted to the U.S. and other Anglo-Saxon countries. Although recent efforts have been undertaken to generalize the findings to other Western-European countries (for example to Germany; see Pforr et al. 2015) or Russia (Avdeyeva \& Matland 2013), studies that test the effectiveness of incentives beyond the Western world - in particular with respect to web surveys - are very scarce.

In this study, we explore to what extent current knowledge on incentive effects can be generalized to non-Western contexts, in particular to the case of web survey incentives in Ghana. Due to the specificity of the Ghanaian context, there are plausible theoretical reasons to expect that web survey incentives may produce different effects from those in Western contexts (for similar arguments, see Avdeyeva \& Matland 2013). In particular, we anticipate that differences in economic conditions, the cultural traditions and customs, and the general survey climate in Ghana might have an impact on the effectiveness of incentives. First, concerning the economic conditions, it is worthwhile to highlight here that Ghana is a developing country with a GNI per capita of \$1,480 (Atlas Method, current US\$) and an estimated poverty headcount ratio of $24.2 \%$ in 2015 (World Development Indicators). While university students (i.e. our research population) generally constitute a relatively privileged section of Ghanaian society, a considerable proportion of them nonetheless faced serious 
socioeconomic hardship during their youth and quite a few students continued to have difficulties making ends meet. Illustratively, 39.3\% of students interviewed as part of our survey mentioned that during their childhood they had gone without food "occasionally" or "frequently" because their family lacked money. In addition, $62.6 \%$ of interviewed students mentioned that they had struggled in past years to pay for their university education. Given these difficult and uncertain economic circumstances and living conditions, we would expect from a rational choice or exchange theory perspective that people would be more willing to participate in activities through which they can generate additional income. Furthermore, compared to the relative standard of living, the incentives used are quite large, and as a result the conditional monetary incentives may well have stronger effects in Ghana compared to Western settings (Avdeyeva \& Matland 2013: 176).

Second, important cultural differences may also contribute to differences in incentives effects. Traditionally, Ghanaian society has been characterized by a strong informal system of reciprocal exchange between family members, friends, neighbours, ethnic group members, etc. as a necessary means of survival (Hydén 2006). Furthermore, Ghana has been identified as one of the most religious countries worldwide (Ruiter \& Van Tubergen 2009), which may positively influence societal norms concerning helping one's fellow man and reciprocating favours, gifts, and assistance. These societal norms may in turn make people more inclined to participate in surveys upon receiving an unconditional monetary incentive. Furthermore, Ghana was found to be one of the least-trusting societies worldwide (Delhey, Newton and Welzel 2011), which might not only decrease response rates, but also undercut the effectiveness of conditional incentives (Avdeyeva \& Matland 2013).

A third factor which may affect the impact of incentives on survey participation is the survey climate; i.e. the societal-level factors that contribute to the willingness to participate in surveys (Groves and Couper 1998: 155). In this respect it is important to note that prospective 
respondents in developing countries are not overburdened with surveys to the same degree as prospective respondents in Western settings. Consequently, we would expect relatively higher response rates in these non-Western settings, which in turn however may be associated with weaker incentives effects.

Finally, one factor that may mediate the impact of incentives on survey participation in a Ghanaian web survey context is the difference in Internet infrastructure found in most SubSaharan African countries compared to Western countries. While the Internet in Europe and Anglo-Saxon countries developed on the back of a landline telephone infrastructure, SubSaharan countries rely more heavily on mobile phone technologies, not only for phone communication but also for the Internet (Aker \& Mbiti 2010; De Bruijn 2009). Figure 1 shows that in our survey of Ghanaian university students more than half of the respondents (53.4\%) used mobile devices to participate in the web survey. In comparison, during the same period in Germany only $19.9 \%$ of the participants aged $20-25$ in the German Internet Panel used mobile devices (Blom, Herzing, Cornesse, Sakshaug, Krieger, \& Bossert 2016). At the same time, methodologists have found mobile web participants less likely to respond to survey requests (e.g. Mavletova 2013; de Bruijne \& Wijnant 2013). Since sample members, however, were invited to the survey via both email and text message, the mobile mode is made particularly attractive. Incentives effects for mobile web surveys are largely unexplored, even in Western countries (cf. Mavletova \& Couper 2016). Given the specific mobile survey setting in African countries, the effects of conditional and unconditional cash incentives may differ from effects found in Western countries.

(Figure 1 about here)

\section{Hypotheses}

Due to the relative scarcity of previous research on survey incentives in non-Western contexts, the character of our study is necessarily exploratory, and contrasting hypotheses can 
be derived. Building upon the findings obtained in a Western context, we expect that unconditional incentives yield higher response rates than conditional ones $(\mathrm{H} 1)$, that higher incentive values will lead to higher response rates $(\mathrm{H} 2 \mathrm{a})$, and that additional value increases have diminishing returns in terms of response (H2b). Response quality will be higher in conditions with unconditional incentives (H3) and with incentives of higher values (H4). Due to specific contextual factors, however, the effectiveness of incentives in Ghana may differ from Western contexts. On the one hand, because of the unfavourable economic context, conditional incentives could possibly be more effective than unconditional ones in Ghana (H5). Finally, the favourable survey climate could lead to a high baseline response rate, with little differences between the various incentive conditions (H6).

\section{Data \& methods}

\section{Data Set: the National Service Scheme Survey (N3S)}

The N3S surveys prospective participants in Ghana's National Service Scheme (NSS). The NSS is a compulsory national service program, which requires all Ghanaian students who obtain a Bachelor degree to complete one year of national social service, usually outside their area of origin. The purpose of the N3S is to study the extent to which Ghana's NSS program contributes to improving inter-group relations and fostering stronger national identities among its participants. To gather information before and after participation in the NSS, we implemented a three-wave online panel of two cohorts of Ghanaian students. We sampled $3^{\text {rd }}$ and $4^{\text {th }}$ year Bachelor students from three public universities with a wide ethno-regional spread (University of Ghana in Legon, Kwame Nkrumah University of Science and Technology in Kumasi, and University for Development Studies with campuses at Tamale, Nyampkala, Wa and Navrongo) and a variety of bachelor programs - agriculture, 
administration, chemistry, computer sciences, economics/development studies, engineering, English, nursing, geography, and politics (see Figure 1 for details on the sampling process).

In a first stage, we visited a mandatory $3^{\text {rd }}$ and $4^{\text {th }}$ year course for each of the Bachelor programs. At the beginning of the class, we asked students to fill out a 4-page paper-andpencil questionnaire. The main purpose of this in-class survey was to obtain email addresses and phone numbers from the students so that they could be invited to participate in the web survey. The other questions in this background questionnaire give valuable information on the students, which we use in the analyses below. In total, 5,825 students completed the questionnaire. Only a very small number of students refused to participate in the survey, either by not accepting a questionnaire, or by handing it back empty.

In a second stage, the 5,570 students who filled out the background questionnaire were invited by email and text message to participate in an online survey. The incentives experiment reported here concerns participation in this second stage of the survey, i.e. the first web survey.

This two-stage procedure has the considerable advantage that background information is available for respondents as well as non-respondents in stage 2. A drawback is that our results do not concern the whole population of university students, but are conditional on participation in the first stage. However, based on information provided by the professors about class attendance and the low refusal rate, we estimate to have covered $80-90 \%$ of all students enrolled in the selected programs. 255 students did not provide a valid email address, and 1,130 invitation emails bounced, ${ }^{i}$ leaving us with a sample of 4,440 students. Our final sample consists of $64.6 \%$ male students, and has a mean age of 23.29 years $(s t d=2.84)$. 


\section{Experimental Design}

Cash incentives - especially pre-paid ones - are notoriously difficult to deliver to respondents (Wetzels et al. 2008), especially in web surveys (Bosnjak and Tuten 2003; Couper 2000). However, the Ghanaian social context offered an interesting opportunity: quasi-cash incentives as mobile phone credit, so-called "top-up". In Ghana, top-ups are easily transmittable and used almost universally as a mode of economic exchange. Top-ups thus are a functional equivalent of cash in Ghana.

Our experimental design varies both the value and the conditionality of cash incentives (see Figure 2). Regarding the value of incentives, students either received a mobile top-up of 5, 10 or 20 Ghanaian Cedi's (GHS) (50\%, 25\% and $25 \%$ of the sample, respectively). These amounts correspond to approximately $€ 1.20, € 2.40$ and $€ 4.80 .5$ GHS is the price of a dinner in a campus restaurant, while 20 GHS buys a bus ticket to travel from Accra to Kumasi (roughly $250 \mathrm{~km}$ ). Given that university students are a privileged section of Ghanaian society, the incentives we offered were relatively small compared to their spending patterns. With respect to conditionality, the three value-conditions were fully crossed. For students receiving an unconditional incentive, the mobile phone top-up - together with a text message indicating that the top-up was meant as a token of gratitude for their participation in the survey - was sent to the respondents' phones just before they received the survey invitation by email. Respondents in a conditional incentive condition received a text message saying that they would receive a top-up upon completing the survey. Note that the experimental design does not contain a no-incentive comparison group. The reason is that, given the previous research in the Western World, there were strong expectations that giving no incentives at all would lead to lower response, which could have damaged the data quality of the N3S research project. 
Because classmates are likely to communicate with each other and differences in amounts might be perceived as unfair (Singer and Ye 2013), we decided to randomize classes of students enrolled in the same bachelor program rather than individual students over the six experimental conditions. In order to obtain a balanced distribution with respect to relevant covariates, 64 class-groups were allocated to the six conditions (see Figure 2) using covariateadaptive randomization (Hu et al. 2014). Specifically, the size of the group, the bachelor year, the university and the discipline were taken into account in this randomization. As a consequence, the experimental group sizes in terms of individuals differ slightly from the projected sizes.

\section{Indicators}

In the context of a web survey, it is useful to distinguish between three indicators of survey participation. A first indicator is the starting rate, i.e. the percentage of the invited sample units that started the survey (i.e. clicked on the invitation link, and loaded at least the first page of the survey). Second, we look at the completion rate (for a similar approach, see Göritz 2006b). This is the percentage of starters that actually complete the survey (i.e. reach the final survey page). As such, completion is the counterpart of drop-out. The distinction between starting rate and completion rate makes it possible so disentangle incentive effects on different states of the survey process. Third, we analyse the response rate, defined as the percentage of invited sample units that completes the survey (i.e. reaches the last page). The response rate is a general indicator that combines incentive effects of the different phases in the survey process (starting and completing) and reveals the impact of incentives up to the end of the questionnaire.

Response quality is operationalized by means of two concrete indicators. First, this study includes the most often-used measure of response quality in incentive research, namely 
the prevalence of item nonresponse. Concretely, we calculate the percentage of missing answers over a set of 85 items that were presented to all respondents (thus not included in routings or filters). Second, we analyse the occurrence of so-called straight-lining, i.e. of selecting the same response option for a set of items that are presented jointly in a matrix question, such that the responses form a straight vertical line on the screen. Straight-lining is often seen as an indicator of satisficing (Kaminska, McCutcheon and Billiet 2010). The N3S contains 11 item batteries, each consisting of multiple items that use the same answer scale and are presented on the same screen. For each respondent, we calculated the percentage of scales on which straight-lining behaviour was observed. To avoid confounding response quality and survey participation, the indicators of response quality were calculated only for respondents who completed the survey $(\mathrm{N}=2,892)$.

In order to control for the differential composition of the class groups, the model controlled for the following background variables: gender, age (in years), ethnicity (i.e. a selfclassification into the major ethnic groups in Ghana), university, year of study $\left(3^{\text {rd }}\right.$ vs $4^{\text {th }} \mathrm{BA}$ year) and the answer on the question whether they look forward to their national service (on a scale from 0 - not at all to 10 - very much). Especially the latter two variables are of interest. Given $4^{\text {th }}$ year students were invited to take the survey four weeks before the start of their national service, and given that the national service is the topic of the N3S, these variables indicate topic salience and attitude towards the topic of the survey.

Descriptive statistics for all variables used can be found in the Appendix. 


\section{Results}

\section{Effects of incentives on survey participation}

Table 1 and Figure 2 present the starting, completion and response rates for each of the six incentive conditions. First, at face value the incentive conditions show substantively relevant variation in starting rates. The difference between the condition with the lowest proportion of starters - as expected the promised 5 GHS condition - and the condition with the highest starting rate (prepaid 10 GHS) is 14 percentage points, and the corresponding odds ratio equals 1.91. Notwithstanding a notable exception, the pattern of differences in starting rates confirms current knowledge. Generally speaking, unconditional incentives seem to be more successful in motivating respondents to start the survey: For each of the values, the starting rate for the prepaid incentive is higher than the one for the promised incentive (although the difference in the 20 GHS-conditions is marginal). Second, higher amounts indeed seem to lead to higher starting rates. At the same time, the starting rates suggest diminishing returns to value increases. For the conditional incentives, moving from 10 to 20 GHS yields about the same increase in starting rate as moving from 5 to 10 GHS, while the value increase is twice as large. In case of the unconditional incentives, moving from 10 to 20 GHS even leads to a decrease in the starting rate. It is not clear whether this surprising result is due to sampling fluctuations or reveals a substantively relevant pattern. James and Bolstein (1992) also report that their highest prepaid incentive - a 40\$ check included in a mail survey - results in lower response than lower denominations. James and Bolstein (1992, p. 447) refer to Dillman (1978) to argue that incentives can become too large: "The closer the monetary incentive comes to the value of the service performed, the more the transaction tends to move into the realm of economic exchange and the easier it becomes for many people to refuse it" (Dillman 1978, p. 16). 
The completion rates reveal a very different dynamic. First, completion rates tend to be slightly higher for the promised than for the prepaid incentives (although differences are very small). Apparently, prepaid incentives are more successful in stimulating Ghanaian students to start the survey, while promised incentives are a slightly stronger motivating factor not to drop out. This seems to contradict a meta-analysis of Western web surveys that found that prepaid and promised incentives have a very similar effect on completion (Göritz 2006a, p. 64). Second, the differences in completion rates are neatly aligned with the value of the incentives: The conditions with higher incentives show higher completion rates.

The combined effect of both processes - starting and not dropping out - is visible in the overall response rate. Three conditions, namely prepaid 10 GHS, prepaid 20 GHS and promised 20 GHS, produce very similar response rates and outperform the worst condition (promised 5 GHS). The remaining two conditions -prepaid 5 GHS and promised 10 GHS associate with medium response rates.

(Table 1 \& Figure 2 about here)

However, the results presented in Table 1 and Figure 2 should be interpreted with great caution. First, it remains to be seen to what extent the reported differences in survey cooperation are statistically significant. And second, the reported figures are flat averages, without taking into account the fact that class groups - with varying compositions in terms of individuals' characteristics - are randomized over the experimental conditions rather than individuals. In order to calculate the significance of the incentive effects, taking into account the clustered nature of the data into account and controlling for differential compositions of classes, we make use of multilevel analysis (Hox 2010). Table 2 presents the results of multilevel logistic regression models for each of the three dichotomous indicators of survey cooperation (namely start, completion and response). The models reveal statistically 
significant differences in the three indicators of survey cooperation between the incentives conditions, although controlling for individual characteristics leads to certain changes in the pattern of differences.

Regarding the starting rate (see Model 1), three conditions - prepaid 10 GHS, prepaid 20 GHS and promised 20 GHS - significantly outperform the reference condition (promised 5 GHS). Although the prepaid 5 GHS-condition yields a slightly higher starting rate than the promised 5 GHS-condition (odds ratio: 1.23), it cannot be ruled out that this difference is due to chance. Controlling for individual background of the respondents, a promised incentive of 20 GHS seems to have the strongest effect on survey participation. However, pairwise comparisons show that there are no significant differences in starting rate between prepaid 10 GHS, prepaid 20 GHS and promised 20 GHS. Furthermore, females, younger students and $4^{\text {th }}$-year students (for whom the survey topic on the national service is more salient) are more likely to start the survey.

Promised incentives with higher values (10 and 20 GHS) lead to significantly higher completion rates than the promised 5 GHS group (see Model 2). None of prepaid incentive conditions, however, deviate significantly from the baseline. Apparently, the prospect of receiving a sizeable top-up motivates Ghanaian students to complete the survey, whereas just having received a top-up produces no such effect. Regarding effects of background variables, completion rates are lower among females and students at the University of Kumasi (for which we have no explanation). Contrary to the starting rate, the completion rate shows no significant variation at the class-group level. This suggests that the decision to start the survey has a class dynamic: Probably, the decision to start with the survey is made public in the group of peers via communication between classmates, which can reinforce the norm of reciprocity. The decision to (dis)continue the survey, conversely is done privately and boils down to a purely individual decision. 
These differentiated patterns of starting and retaining are reflected in the impact of incentives on overall response rates (Model 3). As a result of the high starting rate combined with a high completion rate, the promised 20 GHS condition has the highest response rate $(\mathrm{OR}=2.37)$. The response rate does not only have a higher proportion completers than the baseline condition of 5 GHS promised; Pairwise comparisons indicate that the response rate of the promised 20 GHS-group is higher than in any other incentive condition. Furthermore, prepaid incentives of 10 and 20 GHS turn out to increase overall response rates significantly beyond the level of the promised 5 GHS condition.

\section{(Table 2 about here)}

\section{Effects of incentives on response quality}

Incentives can effectively motivate Ghanaian students to start taking a web survey and to prevent them from dropping out. However, might incentives have unfavourable consequences for the quality of responses provided? In this section, we systematically compare two indicators of response quality - item nonresponse and straight-lining - across incentive conditions (see Table 1).

Our results indicate that there is little reason to believe that incentives produce harmful effects on data quality. The percentage of items left blank across the survey varies less than two percentage points across the incentive conditions. Furthermore, this variation in item nonresponse shows no clear pattern across incentive condition. The lowest proportion of item nonresponse is found for the promised 10 GHS condition, while the highest level is found for the promised 20 GHS, which we would have expected to trigger very similar effects. Furthermore, for straight-lining between-condition differences are rather small and not clearly patterned. The lowest prevalence is found among respondents in the prepaid 20 GHScondition, who show straight-lining behaviour on $18.87 \%$ of the scales. The highest 
percentage of straight-lining is found among respondents in the promised 10 GHS-group with $21.11 \%$ of scales.

In order to take the clustering of the data (students within classes) and the compositional differences of classes into account, we again analysed the proportions of item nonresponse and straight-lining per respondent with multilevel models. Multilevel regressions confirm that there is no relationship between the incentive conditions and the indicators of response quality investigated. Neither item nonresponse, nor straight-lining shows any significant differences across the incentive groups (for detailed results, see Appendix Table 2).

\section{Conclusion and discussion}

Numerous studies into the impact of incentives on survey participation have convincingly shown that (1) incentives increase response rates; (2) unconditional (prepaid) incentives are more effective than conditional (promised) incentives; (3) monetary incentives are more effective than vouchers and in-kind incentives; and (4) the higher value of an incentive, the stronger is the effect it produces, albeit marginal returns diminish (Singer and Ye 2013). While unconditional prepaid incentives can be difficult to implement in web surveys, overall these findings apply to web surveys as well as other survey modes. In the past decade, scholars have expanded their scope of interest beyond the impact of incentives on survey participation and have started investigating the effect of incentives on indicators of response quality as well, notably on item nonresponse (see, for example, Curtin, Singer, and Presser 2007; Davern et al. 2003; Medway 2012). One major shortcoming of this prolific field of study, however, is the fact that all of these studies and empirical analyses have exclusively focused on Western settings. A crucial question, therefore, is: To what extent can we generalize and translate insights concerning incentive effects derived from these Western 
settings to non-Western societies, which are usually characterized by very different economic conditions, cultural traditions and survey climates? The current paper addresses this important question, by analysing the results of a web survey incentives experiment conducted among 4,440 Ghanaian university students, who were interviewed about their upcoming participation in their country's National Service Scheme (NSS).

Several important findings and conclusions emerge from our empirical analyses of the incentives experiment. First, the higher the value of an incentive, the more powerful it is to motivate respondents to start the web survey (confirming $\mathrm{H} 2 \mathrm{a}$ ), although we also find indications for diminishing marginal returns to increasing incentive values (confirming $\mathrm{H} 2 \mathrm{~b}$ ). Second, in the conditions with incentives of lower values, unconditional incentives tend to outperform conditional incentives in encouraging respondents to start the web survey (thus partially supporting H1). These findings largely replicate previous research performed in Western context (for similar conclusions regarding a postal survey in Russia, see Avdeyeva \& Matland 2013). One particular finding, however, contradicts prevailing Western knowledge. Unexpectedly, we found that the providing high (20 GHS) conditional incentives yielded the highest response rate (which is in line with H5). The expectation of a high incentive that will be offered upon completion of the survey not only motivates Ghanaian students to start, but also prevents them from breaking off the survey. This deviating finding can probably be explained by the difficult economic context of Ghana and the constant need for many students to find financial resources to cover living expenses and college fees. The fact that a personal relationship between the research team and the students was already established prior to the web survey (during the in-class background survey) and word-of-mouth recommendations by fellow-students might have additionally created the trust level necessary for this conditional incentive to be so effective. Furthermore, we surprisingly detect that the promised 20 GHS condition does not outperform the baseline, and is nominally worse than the promised 10 
GHS incentive. This suggests that unconditional incentives can become so large that they become perceived as purely economic transactions, making it easier to refuse participation (see also James \& Bolstein 1992). Future research is needed to find out whether this is a reproducible finding, or rather a chance fluctuation.

Regarding the quality of the data, providing differential incentives did not produce any significant effects (thus rejecting $\mathrm{H} 3$ and $\mathrm{H} 4$ ). Incentive value and conditionality were found to be unrelated to both, the amount of item nonresponse and straight-lining response behaviour.

Given the considerable differences between Western and non-Western settings in terms of the nature and state of the prevailing economic and livelihood conditions, the existing cultural traditions, customs and norms, and the general survey climate, it is revealing to observe that incentive effects concerning web survey participation appear to be largely similar across both settings. Because giving incentives to respondents is an important and relatively easy lever for survey designers, this finding is encouraging for survey practitioners in non-Western countries.

However, it should be clear that our study design has a number of limitations and that considerably more research is needed to confirm the effectiveness of incentives in nonWestern contexts. Most notably, the results presented here are based on a survey among university students. Hence, we do not claim generalizability of the effectiveness of incentives in web surveys to the whole Ghanaian population. In fact, such a generalization would be rather meaningless given that large sections of the Ghanaian society have no access to the Internet. Yet, it remains to be seen to what extent our findings can be replicated among other groups in Ghana who are less educated and well-off, but nevertheless have access to the Internet on a regular basis. In line with rational choice theory, one could expect that among poorer individuals, unconditional incentives are even more effective than our results suggest. 
Future research should also attempt to replicate these findings in other non-Western societies. The findings presented here cannot settle the issue on differences between Western and nonWestern societies definitively. A second limitation is that we decided to randomize class groups rather than individuals across the conditions in order to pre-empt class dynamics and contacts between classmates. Although our models control for differences in demographic composition, this decision has decreased statistical power substantially. Finally, although mobile top-ups are almost equivalent to cash in Ghana, further investigation is needed to check whether the provision of real cash incentives would produce different results. 
Author biographies

Bart Meuleman is Associate Professor at the Institute of Social and Political Opinion Research (ISPO) at the University of Leuven, Belgium.

Email: bart.meuleman@kuleuven.be

Arnim Langer is Associate Professor in International Relations, Chair Holder of the UNESCO Chair in Building Sustainable Peace and Director of the Centre for Research on Peace and Development at the University of Leuven, Belgium.

Email: arnim.langer@kuleuven.be

Annelies G. Blom is an assistant professor at the School of Social Sciences, University of Mannheim (Germany), and the principal investigator of the German Internet Panel at the Collaborative Research Center 884 "'Political Economy of Reforms”.

Email: blom@uni-mannheim.de.

\section{Funding:}

This work was supported by the Research Foundation Flanders (FWO) project 'Making Citizens 'National': Analyzing the Impact of Ghana's National Service Scheme (NSS)' (grant reference G049513N) and the KU Leuven Special Research Fund. The first and third authors gratefully acknowledge support from the Collaborative Research Centre "Political Economy of Reforms" (SFB 884) at the University of Mannheim, which is funded by the German Research Foundation (DFG). 


\section{References}

Aker, J. C., \& Mbiti, I. M. (2010). Mobile phones and economic development in Africa. The Journal of Economic Perspectives, 24(3), 207-232.

Alwin, D. F. (1991). Research on survey quality. Sociological Methods \& Research, 20(1), 329. doi: $10.1177 / 0049124191020001001$

Armstrong, J.S., \& Lusk, E.J. (1987). Return postage in mail surveys: A meta-analysis. Public Opinion Quarterly, 39, 111-116. doi: 10.1086/269031

Auspurg, K. \& Schneck, A. (2014). What difference makes a difference?: A meta-regression approach on the effectiveness conditions of incentives in self-administered surveys. MAER-Net 2014 Athens Colloquium, Athens.

Avdeyeva, O. A., \& Matland, R. E. (2013). An Experimental Test of Mail Surveys as a Tool for Social Inquiry in Russia. International journal of public opinion research, 25(2), 173-194. doi: 10.1093/ijpor/eds020

Birnholtz, J. P., Horn, D. B., Finholt, T.A., \& Bae, S.J. (2004). The effects of cash, electronic, and paper gift certificates as respondent incentives for a web-based survey of technologically sophisticated respondents. Social Science Computer Review, 22(3), 355-362. doi: $10.1177 / 0894439304263147$

Bosnjak, M., \& Tuten, T.L. (2003). Prepaid and promised incentives in web surveys. An experiment. Social Science Computer Review, 21(2), 208-217. doi: $10.1177 / 0894439303021002006$

Blom, A. G., Jäckle, A., \& Lynn, P. (2010). The use of contact data in understanding crossnational differences in unit nonresponse. In J.A. Harkness, M. Braun, B. Edwards, T.P. Johnson, L. Lyberg, P.Ph. Mohler, B. Pennell \& T.W. Smith (eds.), Survey methods in multinational, multiregional, and multicultural contexts (pp. 335-354). Hoboken, NJ: Wiley. doi: 10.1002/9780470609927.ch18 
Blom, A.G., Gathmann, C., \& Krieger, U. (2015). Setting Up an Online Panel Representative of the General Population: The German Internet Panel. Field Methods, 27(4), 391-408. doi: $10.1177 / 1525822 X 15574494$

Blom, A. G., Herzing, J. M., Cornesse, C., Sakshaug, J. W., Krieger, U., \& Bossert, D. (2016). Does the Recruitment of Offline Households Increase the Sample Representativeness of Probability-Based Online Panels? Evidence From the German Internet Panel. Social Science Computer Review, Published Online First on June 2, 2016. doi: $10.1177 / 0894439316651584$.

Church, A.H. (1993). Estimating the effect of incentives on mail survey response rates: A meta-analysis. Public Opinion Quarterly, 57(1), 62-79. doi: 10.1086/269355

Couper, M.P. (2000). Web surveys. A review of issues and approaches. Public Opinion Quarterly, 64, 464-49. doi:10.1086/318641

Couper, M.P., \& de Leeuw, E.D. (2003). Nonresponse in cross-cultural and cross-national surveys. In J.A. Harkness, van de Vijver, F.J.R. \& P.Ph. Mohler (eds.), Cross-cultural survey methods (pp. 157-178). NJ: John Wiley.

Curtin, R., Singer, E., \& Presser, S. (2007). Incentives in Random Digit Dial Telephone Surveys: A Replication and Extension. Journal of Official Statistics, 23(1), 91-105.

Davern, M., Rockwood, T.H., Sherrod, R., \& Campbell, S. (2003). Prepaid monetary incentives and data-quality in face-to-face interviews: Data from the 1996 Survey of Income and Program Participation Incentive Experiment. Public Opinions Quarterly, 67(1), 139-147. DOI:10.1086/346012

De Bruijn, M. (2009). Mobile phones: The new talking drums of everyday Africa. African Books Collective.

De Bruijne, M. and Wijnant, A. (2013). Comparing Survey Results Obtained via Mobile Devices and Computers: An Experiment With a Mobile Web Survey on a 
Heterogeneous Group of Mobile Devices Versus a Computer-Assisted Web Survey. Social Science Computer Review. 31(4), 482-504. DOI: 10.1177/0894439313483976

Delhey, J., Newton, K., \& Welzel, C. (2011). How General Is Trust in 'Most People’?

Solving the Radius of Trust Problem. American Sociological Review, 76(5), 786-807. doi: $10.1177 / 0003122411420817$

Deutskens, E., De Ruyter, K., Wetzels, M., \& Oosterveld, P. (2004). Response rate and response quality of internet-based surveys: An experimental study. Marketing Letters, 15(1), 21-36. doi: 10.1023/B:MARK.0000021968.86465.00

Dillman, D.A. (1978). Mail and telephone surveys. New York: Wiley.

Dillman, D.A. (2000). Mail and Internet surveys: The tailored design method. New York: John Wiley and Sons.

Edwards, P., Roberts, I., Clarke, M., DiGuiseppi, C., Pratap, S., Wentz, R., \& Kwan, I. (2002). Increasing response rates to postal questionnaires: systematic review. British Medical Journal, 324(7347), 1183-1192. doi: 10.1136/bmj.324.7347.1183

Fishbein, M., \& Icek, A. (1975). Belief, attitude, intention and behaviour: An introduction to theory and research. Reading, MA: Addison-Wesley.

Gelman, A., Stevens, M., \& Chan, V. (2003). Regression modeling and meta-analysis for decision making: A cost-benefit analysis of incentives in telephone surveys. Journal of Business \& Economic Statistics, 21(2), 213-225. doi: 10.1198/073500103288618909

Gouldner, A.W. (1960). The norm of reciprocity: A preliminary statement. American Sociological Review, 25(2), 161-178.

Göritz, A.S. (2004). The impact of material incentives on response quantity, response quality, sample compositions, survey outcome, and cost in online access panel. International Journal of Market Research, 46(3), 327-345. 
Göritz, A.S. (2006a). Incentives in web studies: Methodological issues and a review. International Journal of Internet Science, 1(1), 58-70.

Göritz, A.S. (2006b). Cash lotteries as incentives in online panels. Social Science Computer Review, 24(4), 445-459.

Groves, R.M., Singer, E., \& Corning, A. (2000). Leverage-salience theory of survey participation: Description and Illustration. Public Opinion Quarterly, 64(3), 299-308. doi: $10.1086 / 317990$

Hansen, R.A. (1980). A self-interpretation of the effect of monetary and nonmonetary incentives on mail survey respondent behavior. Journal of Marketing Research, 17(1), 77-83. doi: $10.2307 / 3151120$

Heberlein, T.A., \& Baumgartner, R. (1978). Factors affecting response rates to mailed questionnaires: A quantitative analysis of the published literature. American Sociological Review, 43, 447-462.

Homans, G.C. (1950). The human group. New York: Harcourt, Brace and Company.

Hopkins, K.D., \& Gullickson, A.R. (1992). Response Rates in Survey Research: A Metaanalysis of the Effects of Monetary Gratuities. Journal of Experimental Education, 61, 52-62. doi: 10.1080/00220973.1992.9943849

Hox, J.J. (2010). Multilevel analysis. Techniques and applications. New York: Routledge.

Hu, F., Hu, Y., Ma, Z., \& Rosenberger, W.F. (2014). Adaptive Randomization for Balancing Over Covariates. Wiley Interdisciplinary Reviews: Computational Statistics, 6(4), 288303. doi: 10.1002/wics. 1309

Hydén, G. (2006). African politics in comparative perspective. Cambridge: Cambridge University Press. 
James, J.M., \& Bolstein, R. (1990). The effect of monetary incentives and follow-up mailings on the response rate and response quality in mail surveys. Public Opinion Quarterly, 54(3), 346-361. doi: 10.1086/269211

James, J.M., \& Bolstein, R. (1992). Large monetary incentives and their effect on mail survey response rates. Public Opinion Quarterly, 56(4), 442-453. doi: 10.1086/269336

Jäckle, A. \& Lynn, P. (2008). Respondent incentives in a multi-mode panel survey: Cumulative effects on nonresponse and bias. Survey Methodology, 34(1), 105-117.

Kaminska, O., McCutcheon, A.L., \& Billiet, J. (2010). Satisficing among reluctant respondents in a cross-national context. Public Opinion Quarterly, 74, 956-984. doi: $10.1093 / \mathrm{poq} / \mathrm{nfq} 062$

Mauss, M. (1923). Essai sur le don forme et raison de l'échange dans les sociétés archaïques. L'Année sociologique (1896/1897-1924/1925), 30-186.

Mavletova, A. (2013). Data quality in PC and mobile web surveys. Social Science Computer Review, 31(6), 725-743, DOI: 10.1177/0894439313485201.

Mavletova, A., \& Couper, M. P. (2016). Device use in web surveys: the effect of differential incentives. International Journal of Market Research, 58(4), 523-544.

Medway, R. (2012). Beyond Response Rates: The Effect of Prepaid Incentives on Measurement Error. Ph. D. thesis, Graduate School of the University of Maryland.

Mutti, S., Kennedy, R.D., Thompson, M.E., \& Fong, G.T. (2014). Prepaid monetary incentives - Predictors of taking the money and completing the survey: Results from the International Tobacco Control (ITC) four-country survey. Sociological Methods \& Research, 43(2), 338-355. doi: 10.1177/0049124113506406

Petrolia, D.R., 1 Bhattacharjee, S. (2009). Revisiting incentive effects: Evidence from a random sample mail survey on consumer preferences for fuel ethanol. Public Opinion Quarterly, 73(3), 537-550. doi: 10.1093/poq/nfp038 
Philipson, T. (1997). Data markets and the production of surveys. The Review of Economic Studies, 64(1), 47-72. doi: 10.2307/2971740

Pforr, K., Blohm, M., Blom, A.G., Erdel, B., Felderer, B., Frässdorf, M. ... \& Rammstedt, B. (2015). Are incentive effects on response rates and nonresponse bias in large-scale, face-to-face surveys generalizable to Germany? Public Opinion Quarterly, 79(3), 740768. doi: $10.1093 / \mathrm{poq} / \mathrm{nfv} 014$

Ruiter, S., \& Van Tubergen, F. (2009). Religious Attendance in Cross-National Perspective: A Multilevel Analysis of 60 Countries. American Journal of Sociology, 115(3), 863895. doi: $10.1086 / 603536$

Scherpenzeel, A., \& Toepoel, V. (2012). Recruiting a probability sample for an online panel effects of contact mode, incentives, and information. Public Opinion Quarterly, 76(3), 470-490. doi:10.1093/poq/nfs037

Shettle, C., \& Mooney, G. (1999). Monetary incentives in U.S. government surveys. Journal of Official Statistics, 15(2), 231-250.

Shuttleworth, F.K. (1931). A study of questionnaire technique. Journal of Educational Psychology 22:652-58. doi: 10.1037/h0074591

Singer, E. (2011). Toward a benefit-cost theory of survey participation: evidence, further tests, and implications. Journal of Official Statistics, 27(2), 379.

Singer, E, Van Hoewyk, J., Gebler, N., Raghunathan, T., \& McConagle, K. (1999). The effect of incentives on response rates in interviewer-mediated surveys. Journal of Official Statistics, 15(2), 217-230.

Singer, E., \& Ye, C. (2013). The use and effects of incentives in surveys. ANNALS of the American Academy of Political and Social Science, 645, 112-141. doi:

$10.1177 / 0002716212458082$ 
Singer, E., Van Hoewyk, J. \& Maher, M.P. (2000). Experiments with incentives in telephone surveys. Public Opinion Quarterly, 64(2), 171-188. doi: 10.1086/317761

Simmons, E., \& Wilmot, A. (2004). Incentive payments on social surveys: A literature review. Social Survey Methodology Bulletin, 53, 1-11.

Teisl, M.F., Roe, B., \& Vayda, M. (2005). Incentive effects on response rates, data quality, and survey administration costs. International Journal of Public Opinion Research, 18(3), 364-373. doi: 10.1093/ijpor/edh106

van Veen, F., Göritz, A.S., \& Sattler, S. (2016). Response Effects of Prenotification, Prepaid Cash, Prepaid Vouchers, and Postpaid Vouchers An Experimental Comparison. Social Science Computer Review, 34(3), 333-346.

Wetzels, W., Schmeets, H., van den Brakel, J., \& Feskens, R. (2008). Impact of prepaid incentives in face-to-face surveys: A large-scale experiment with postage stamps. International Journal of Public Opinion Research, 20(4), 507-516. doi: 10.1093/ijpor/edn050

Yu, J., \& Cooper, H. (1983). A quantitative review of research design effects on response rates to questionnaires. Journal of marketing research, 20(1), 36-44. doi:

$10.2307 / 3151410$ 
Figure 1. Participation on mobile and computer devices in the N3S survey of Ghanaian students

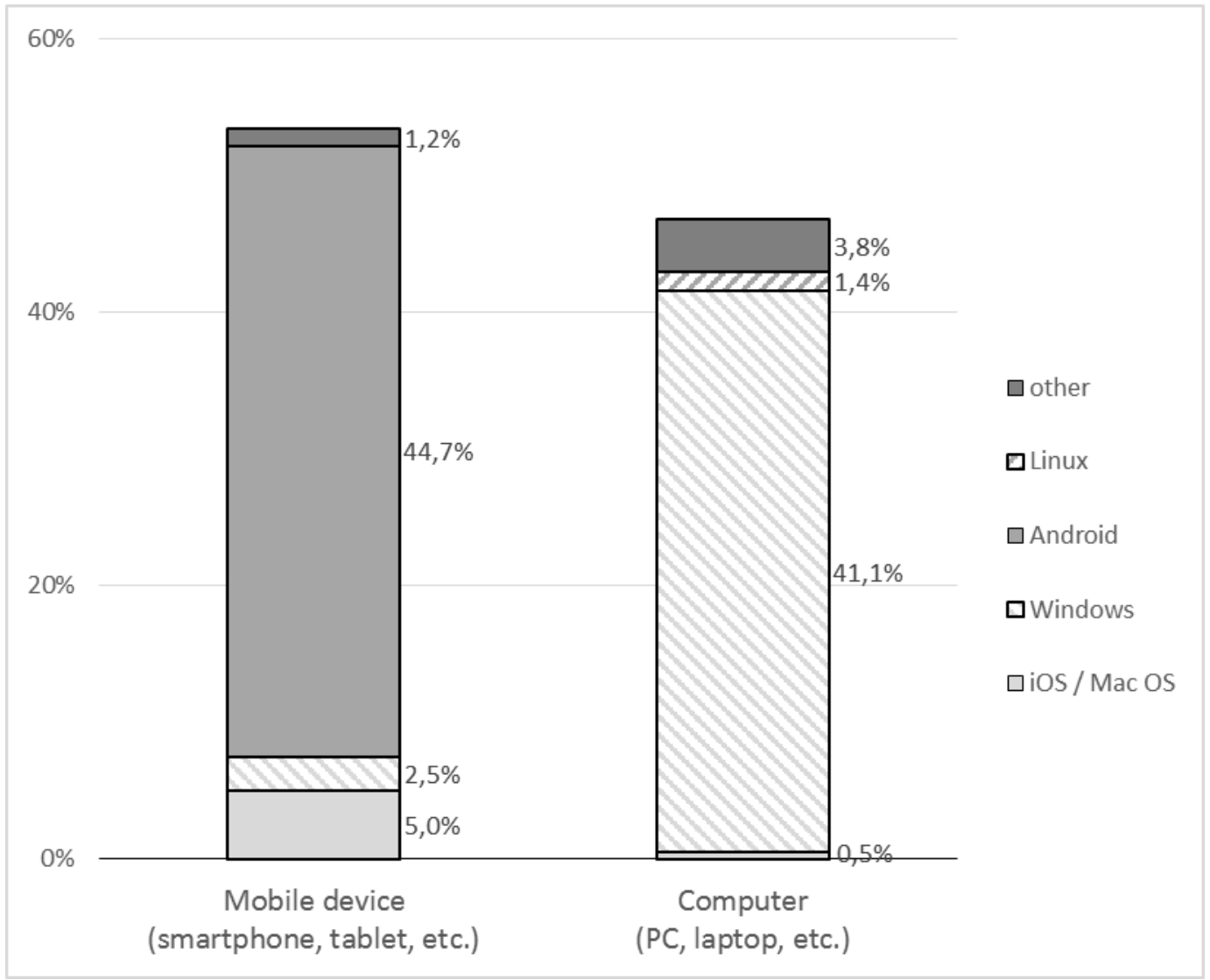


Table 1. Indicators of survey response and data quality by incentives condition

\begin{tabular}{lcccccccc}
\hline & \multicolumn{2}{c}{ Starting } & \multicolumn{2}{c}{ Completion } & \multicolumn{2}{c}{ Response } & \% item & \% straight- \\
\multicolumn{1}{c}{ Condition } & Rate & OR & Rate & OR & Rate & OR & nonresponse & lining \\
\hline Prepaid 5 GHS & 64.99 & 1.28 & 86.53 & 0.81 & 56.24 & 1.16 & 4.36 & 20.12 \\
Prepaid 10 GHS & 73.49 & 1.91 & 89.30 & 1.05 & 65.63 & 1.72 & 3.51 & 19.95 \\
Prepaid 20 GHS & 69.53 & 1.57 & 92.74 & 1.60 & 64.48 & 1.63 & 3.78 & 18.87 \\
Promised 5 GHS & 59.25 & & 88.85 & & 52.64 & & 4.15 & 20.28 \\
Promised 10 GHS & 63.23 & 1.18 & 93.18 & 1.71 & 58.91 & 1.29 & 3.27 & 21.11 \\
Promised 20 GHS & 68.31 & 1.48 & 94.58 & 2.19 & 64.61 & 1.64 & 4.68 & 20.73 \\
\hline$N$ & 4440 & \multicolumn{7}{c}{2892} \\
\hline
\end{tabular}

Note. OR: Odds ratio, compared with the theoretically worst incentive condition (conditional 5 GHS) 
Table 2. Multilevel logistic regression models for starting the survey, completion and overall response (estimated odds ratios and their $95 \%$ confidence intervals)

\begin{tabular}{|c|c|c|c|c|c|c|}
\hline & \multicolumn{2}{|c|}{ Model 1: Starting rate } & \multicolumn{2}{|c|}{ Model 2: Completion rate } & \multicolumn{2}{|c|}{ Model 3: Response rate } \\
\hline & $\operatorname{Exp}(B)$ & $95 \%$ CI & $\operatorname{Exp}(B)$ & $95 \% \mathrm{CI}$ & $\operatorname{Exp}(B)$ & $95 \%$ CI \\
\hline Intercept & $6.16 * * *$ & $(3.01 ; 12.61)$ & $6.20 *$ & $(1.37 ; 28.13)$ & $3.64 * * *$ & $(1.81 ; 7.34)$ \\
\hline \multicolumn{7}{|l|}{ Incentive } \\
\hline Prepaid 5 GHS & 1.23 & $(0.94 ; 1.62)$ & 1.01 & $(0.71 ; 1.43)$ & 1.21 & $(0.94 ; 1.56)$ \\
\hline Prepaid $10 \mathrm{GHS}$ & $1.63 * *$ & $(1.17 ; 2.28)$ & 0.85 & $(0.56 ; 1.30)$ & $1.48^{*}$ & $(1.09 ; 2.01)$ \\
\hline Prepaid 20 GHS & $1.43 *$ & $(1.07 ; 1.93)$ & 1.39 & $(0.88 ; 2.18)$ & $1.47 * *$ & $(1.12 ; 1.95)$ \\
\hline Promised 5 GHS (ref.cat.) & & & & $(1.02 ; 2.92)$ & & \\
\hline Promised $10 \mathrm{GHS}$ & 1.09 & $(0.80 ; 1.49)$ & $1.72 *$ & & 1.17 & $(0.88 ; 1.57)$ \\
\hline Promised 20 GHS & $2.00 * * *$ & $(1.33 ; 3.00)$ & $3.15^{* * *}$ & $(1.74 ; 5.69)$ & $2.37 * * *$ & $(1.63 ; 3.45)$ \\
\hline \multicolumn{7}{|l|}{ Gender } \\
\hline $\begin{array}{r}\text { Male } \\
\text { Female (ref.) }\end{array}$ & $1.39 * * *$ & $(1.20 ; 1.61)$ & $1.32 *$ & $(1.01 ; 1.73)$ & $1.41 * * *$ & $(1.23 ; 1.63)$ \\
\hline Age & $0.94 * * *$ & $(0.92 ; 0.97)$ & 1.01 & $(0.96 ; 1.07)$ & $0.95 * * *$ & $(0.93 ; 0.97)$ \\
\hline \multicolumn{7}{|l|}{ Ethnicity } \\
\hline Ga-Dangme & 0.97 & $(0.78 ; 1.22)$ & 1.12 & $(0.73 ; 1.72)$ & 1.00 & $(0.80 ; 1.24)$ \\
\hline Ewe & 1.16 & $(0.95 ; 1.41)$ & 1.42 & $(0.95 ; 2.11)$ & $1.24 *$ & $(1.02 ; 1.50)$ \\
\hline Guan & 0.79 & $(0.54 ; 1.16)$ & 1.33 & $(0.57 ; 3.14)$ & 0.87 & $(0.60 ; 1.27)$ \\
\hline Gurma & 1.19 & $(0.79 ; 1.79)$ & 1.16 & $(0.49 ; 2.75)$ & 1.22 & $(0.82 ; 1.81)$ \\
\hline Mole-Dagbani & 0.99 & $(0.75 ; 1.30)$ & 1.06 & $(0.61 ; 1.85)$ & 1.00 & $(0.77 ; 1.30)$ \\
\hline Grusi & 0.92 & $(0.51 ; 1.65)$ & 1.68 & $(0.39 ; 7.20)$ & 1.00 & $(0.57 ; 1.77)$ \\
\hline Mande & 1.23 & $(0.54 ; 2.83)$ & 1.86 & $(0.24 ; 14.20)$ & 1.34 & $(0.60 ; 3.00)$ \\
\hline Akan (ref.) & & & & & & \\
\hline \multicolumn{7}{|l|}{ Year of study } \\
\hline $\begin{array}{r}3 r d B A \\
\text { 4th BA (ref.) }\end{array}$ & 0.61 & $(0.50 ; 0.74)$ & 0.92 & $(0.69 ; 1.21)$ & $0.64 * * *$ & $(0.53 ; 0.77)$ \\
\hline \multicolumn{7}{|l|}{ University } \\
\hline$U G-A c c r a$ & 1.19 & $(0.93 ; 1.52)$ & 0.79 & $(0.51 ; 1.23)$ & 1.10 & $(0.87 ; 1.39)$ \\
\hline KNUST - Kumasi & 1.12 & $(0.85 ; 1.49)$ & $0.46^{* * *}$ & $(0.29 ; 0.71)$ & 0.91 & $(0.70 ; 1.19)$ \\
\hline UDS - Tamale (ref.) & & & & & & \\
\hline Looking forward to NSS & 1.00 & $(0.97 ; 1.03)$ & 1.02 & $(0.97 ; 1.08)$ & 1.00 & $(0.98 ; 1.03)$ \\
\hline Variance class-level & \multicolumn{2}{|c|}{$0.220 * * *$} & \multicolumn{2}{|r|}{0.000} & \multicolumn{2}{|c|}{$0.169 * * *$} \\
\hline $\mathrm{ICC}$ & \multicolumn{2}{|c|}{0.063} & \multicolumn{2}{|r|}{0.000} & \multicolumn{2}{|c|}{0.049} \\
\hline $\mathrm{N}$ & \multicolumn{2}{|r|}{4089} & \multicolumn{2}{|r|}{2709} & \multicolumn{2}{|c|}{4089} \\
\hline
\end{tabular}

$* \mathrm{p}<.05 ; * * \mathrm{p}<.01 ; * * * \mathrm{p}<.001$ 
Figure 2. Design of the N3S - including distribution of students and classes over the incentive conditions

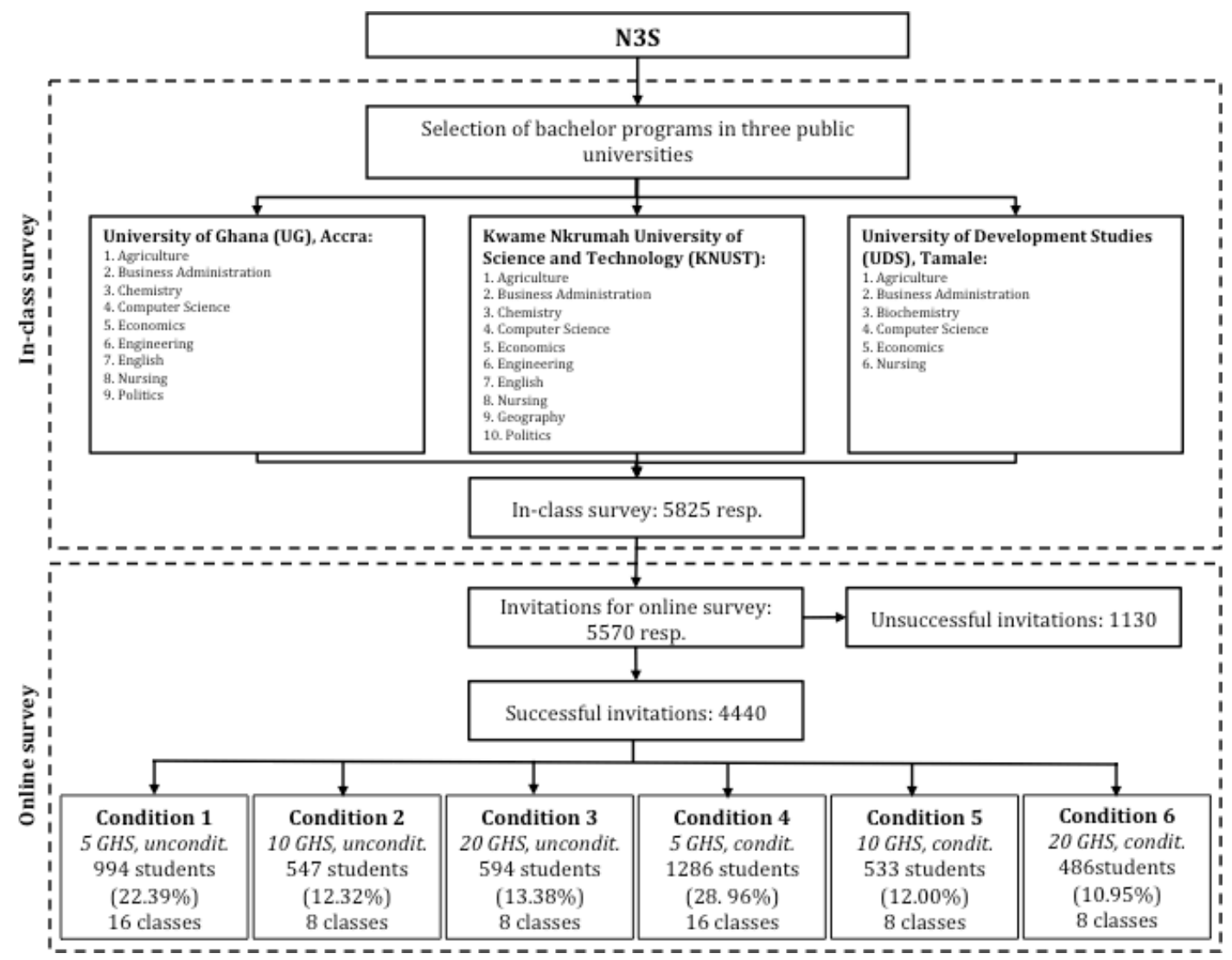


Figure 3. Starting, completion and response rates by condition
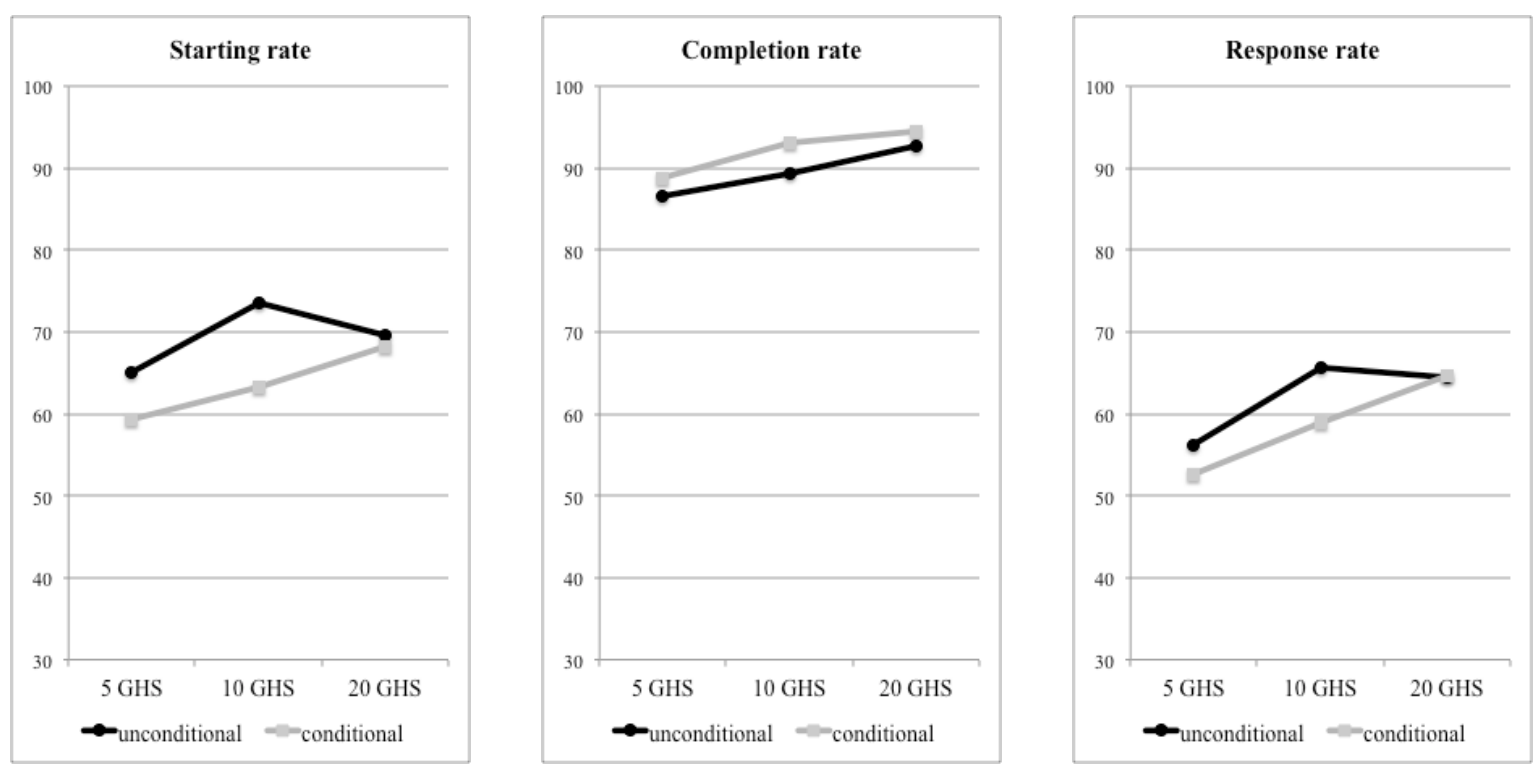
Appendix Table 1. Descriptive statistics

\begin{tabular}{|c|c|c|c|}
\hline & & $\%$ & $\mathrm{~N}$ \\
\hline \multirow{7}{*}{ Condition } & Unconditional 5 GHS & 22.39 & 994 \\
\hline & Unconditional $10 \mathrm{GHS}$ & 12.32 & 547 \\
\hline & Unconditional $20 \mathrm{GHS}$ & 13.38 & 594 \\
\hline & Conditional 5 GHS & 28.96 & 1286 \\
\hline & Conditional $10 \mathrm{GHS}$ & 12 & 533 \\
\hline & Conditional 20 GHS & 10.95 & 486 \\
\hline & Total & 100 & 4440 \\
\hline \multirow{3}{*}{ Started survey } & Yes & 65.14 & 2892 \\
\hline & No & 34.86 & 1548 \\
\hline & Total & 100 & 4440 \\
\hline \multirow{3}{*}{$\begin{array}{l}\text { Completed } \\
\text { survey }\end{array}$} & Yes & 58.69 & 2606 \\
\hline & No & 41.31 & 1834 \\
\hline & Total & 100 & 4440 \\
\hline \multirow{3}{*}{ Gender } & Male & 64.55 & 2864 \\
\hline & Female & 35.45 & 1573 \\
\hline & Total & 100 & 4437 \\
\hline \multirow{9}{*}{ Ethnicity } & Ga-Dangme & 10.55 & 449 \\
\hline & Ewe & 14.81 & 630 \\
\hline & Guan & 3.2 & 136 \\
\hline & Gurma & 2.94 & 125 \\
\hline & Mole-Dagbani & 7.05 & 300 \\
\hline & Grusi & 1.32 & 56 \\
\hline & Mande & 0.71 & 30 \\
\hline & Akan & 59.44 & 2529 \\
\hline & Total & 100 & 4255 \\
\hline \multirow{3}{*}{ Year of study } & $3 \mathrm{rd} \mathrm{BA}$ & 48.41 & 2146 \\
\hline & 4th BA & 51.59 & 2287 \\
\hline & Total & 100 & 4433 \\
\hline \multirow{4}{*}{ University } & UG - Accra & 42.82 & 1901 \\
\hline & KNUST - Kumasi & 36.71 & 1630 \\
\hline & UDS - Tamale & 20.47 & 909 \\
\hline & Total & 100 & 4440 \\
\hline
\end{tabular}

\begin{tabular}{lccccc}
\hline & Mean & Std Dev & Min & Max & N \\
\hline \% item nonresponse & 4.01 & 7.89 & 0 & 75.61 & 2606 \\
\% straight-lining & 20.15 & 15.13 & 0 & 90.91 & 2606 \\
Age & 23.29 & 2.83 & 16 & 48 & 4316 \\
Looking forward to NSS & 7.85 & 2.63 & 0 & 10 & 4387 \\
\hline
\end{tabular}


Appendix Table 2. Multilevel regression models for indicators of response quality

\begin{tabular}{|c|c|c|}
\hline & $\begin{array}{l}\text { Model 4: Item non- } \\
\text { response } \\
\text { Par.Est. } \\
\end{array}$ & $\begin{array}{c}\text { Model 5: } \\
\text { Straigthlining } \\
\text { Par.Est. } \\
\end{array}$ \\
\hline Intercept & $-5.91 * * *$ & $19.04 * * *$ \\
\hline \multicolumn{3}{|l|}{ Incentive } \\
\hline Prepaid 5 GHS & -0.12 & -0.94 \\
\hline Prepaid 10 GHS & -0.57 & -0.79 \\
\hline Prepaid 20 GHS & -0.19 & -1.10 \\
\hline \multicolumn{3}{|l|}{ Promised 5 GHS (ref.cat.) } \\
\hline Promised $10 \mathrm{GHS}$ & -0.72 & 0.32 \\
\hline Promised 20 GHS & 0.76 & 0.49 \\
\hline \multicolumn{3}{|l|}{ Gender } \\
\hline Male & $-1.29 * * *$ & -0.52 \\
\hline \multicolumn{3}{|l|}{ Female (ref.) } \\
\hline Age & $0.51 * * *$ & -0.02 \\
\hline \multicolumn{3}{|l|}{ Ethnicity } \\
\hline Ga-Dangme & 0.05 & 0.42 \\
\hline Ewe & -0.36 & 0.32 \\
\hline Guan & $-2.25^{*}$ & -0.52 \\
\hline Gurma & $-2.28 *$ & 0.56 \\
\hline Mole-Dagbani & $-1.7 * *$ & -0.46 \\
\hline Grusi & -2.15 & -2.05 \\
\hline Mande & 0.03 & 0.26 \\
\hline Akan (ref.) & & \\
\hline \multicolumn{3}{|l|}{ Year of study } \\
\hline $\begin{array}{r}3 r d B A \\
4 \text { th } B A \text { (ref.) }\end{array}$ & $1.55^{* * *}$ & 0.35 \\
\hline \multicolumn{3}{|l|}{ University } \\
\hline$U G-A c c r a$ & 0.29 & 1.53 \\
\hline KNUST - Kumasi & 0.04 & 1.30 \\
\hline UDS - Tamale (ref.) & & \\
\hline Looking forward to NSS & $-0.18 * *$ & 0.15 \\
\hline Variance RI & 0.00 & 1.54 \\
\hline Residual var. & $59.33 * * *$ & $228.54 * * *$ \\
\hline $\mathrm{ICC}$ & 0.000 & 0.007 \\
\hline $\mathrm{N}$ & 2446 & 2446 \\
\hline
\end{tabular}

$* \mathrm{p}<.05 ; * * \mathrm{p}<.01 ; * * * \mathrm{p}<.001$ 


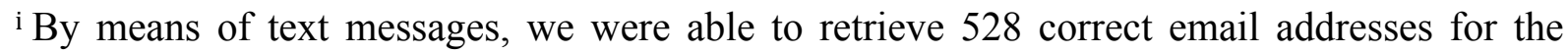
respondents whose invitation mail bounced (which suggests that most incorrect email addresses were spelling/reading mistakes rather than deliberately fake addresses). Because the communication via text message might have interfered with the experimental manipulations, these respondents are not included in the analysis of incentive effects.
\end{abstract}

